\title{
A study on maternal and perinatal out comes in cases of eclampsia admitting to government medical college and general hospital, Anantapuramu, Andhra Pradesh, India
}

\author{
Shamshad Begum Shaikh*, Sandhya Jampala, Shyamala Devi S., Mallika
}

Department of Obstetrics and Gynecology, Government Medical College, Anantapuramu, Andhra Pradesh, India

Received: 06 June 2016

Accepted: 25 June 2016

*Correspondence:

Dr. S. Shamshad Begum,

E-mail:dr.maheshgajula@gmail.com

Copyright: (c) the author(s), publisher and licensee Medip Academy. This is an open-access article distributed under the terms of the Creative Commons Attribution Non-Commercial License, which permits unrestricted non-commercial use, distribution, and reproduction in any medium, provided the original work is properly cited.

\begin{abstract}
Background: Eclampsia is a life threatening emergency that continues to be a major risk factor dictating the outcome of pregnancy and is still the leading etiological factor of maternal mortality worldwide. The aim was to study the incidence of eclampsia at Government General Hospital, Anantapuramu, Andhra Pradesh, India, to evaluate the clinical course and complications and to study the maternal and perinatal outcome in eclamptic patients.

Methods: Current study is a retrospective study carried out based on the data acquired from the case records of all eclampsia patients who admitted in the department of obstetrics and gynecology, government general hospital, Anantapuramu, Andhra Pradesh, India from February 2015 to February 2016. Data was recorded in a pretested proforma and was analyzed using appropriate statistical methods.

Results: Out of a total of 8595 deliveries conducted during the study period, 50 cases of eclampsia were recorded making the incidence of eclampsia to be $0.58 \%$ in the hospital. There were no maternal deaths occurred during the study period. Total numbers of perinatal deaths due to eclampsia were 14 , hence the perinatal mortality rate for eclampsia was 280/1000. Majority of the patients were unbooked (90\%). $78 \%$ of patients were primigravidas and $80 \%$ of patients were less than 25 years of age. Antepartum eclampsia was seen in $72 \%$ of the cases, intrapartum eclampsia in $4 \%$ patients and postpartum eclampsia was found in $24 \%$ of the patients. Vaginal delivery was a common mode of delivery conducted in $56 \%$ of patients while $44 \%$ of the patients required caesarean section.

Conclusions: Eclampsia continues to be an important etiological factor for maternal/perinatal morbidity and mortality. The contributory factors for this being lack of proper antenatal care, low socio economic status and lack of education. There is an urgent need for proper antenatal care, proper medication (magnesium sulfate), intensive monitoring of women with eclampsia and timely hospitalization to improve both the maternal and perinatal outcome. Early presentation and timely decision to terminate pregnancy will improve the maternal and perinatal outcome.
\end{abstract}

Keywords: Antenatal care, Eclampsia, Maternal, Perinatal mortality, Morbidity

\section{INTRODUCTION}

Eclampsia is an established obstetric enigma posing huge burden over the obstetricians since times of its discovery. Eclampsia continues to be a major problem worldwide, particularly in developing countries. The word eclampsia is from the Greek term for lightning. The first known description of the condition was by Hippocrates in the $5^{\text {th }}$ century BCE. Eclampsia is a condition associated with pregnancy where in there will be onset of convulsions in a woman who is having preeclampsia. Pre-eclampsia is disorder characterized by presence of high blood pressure, proteinuria, pedal edema and or other organ dysfunction. Onset may be antepartum, postpartum or 
intrapartum. Most often it is during the second half of pregnancy. In India eclampsia constitutes for one of the leading causes of maternal mortality and morbidity. The incidence of eclampsia in developed countries range from $1: 2000$ to $1: 3448$ pregnancies which is much lower than in developing countries like India. ${ }^{1}$ The incidence of eclampsia in India has been quoted to as high as $1.56 \% .^{2}$

In most cases the onset of pre-eclampsia is insidious and pathological changes occur weeks before clinically detectable hypertension and proteinuria. In addition, symptoms occur only at the end stage of disease, just before the eclamptic episode. It has been established that good antenatal care can prevent the occurrence of eclampsia, though not in all cases. ${ }^{3-5}$

Magnesium sulphate is most preferred anticonvulsive agent known to be very effective in reducing maternal and perinatal morbidity/mortality. Cerebral anoxia, brain damage and coma are the established sequalae of eclampsia. Magnesium sulphate is proved superior drug over diazepam (benzodiazepines) with low seizure recurrence, quick recovery from coma and improved fetal salvage. ${ }^{6}$

Morbidity from eclampsia is associated with acute renal failure, pulmonary edema, cardiopulmonary arrest, and aspiration. $^{7}$ The causes of perinatal death are chronic placental insufficiency, preterm delivery and placental abruption. ${ }^{8,9}$

\section{METHODS}

The current retrospective study was conducted from February 2015 to February 2016 and a total of 50 cases of eclampsia were managed at government general hospital, Anantapuramu, Andhra Pradesh, India. All the obstetrical women admitted in emergency receiving room with convulsions after 20 weeks of gestation or in postpartum period included in this study. Women with other causes of convulsion were excluded. Diagnosis of eclampsia was confirmed by history taking, general and obstetrical examinations. Specific investigations for eclampsia- urine albumin, CBP, LFT, RFT, coagulation profile, platelet count and fundoscopy were performed. All patients were treated with standard intramuscular regimen as recommended by Pritchard's which consists of $4 \mathrm{gm}$ magnesium sulphate given intravenously and 5 gm given intramuscularly on each buttock. Subsequently, $5 \mathrm{gm}$ of magnesium sulphate given intramuscularly every 4 hours upto 24 hours following delivery or convulsion whichever is last. Severe hypertension was treated with labetalol (initial dose $20 \mathrm{mg} \mathrm{IV}$, followed by $40-80 \mathrm{mg}$ every 10 minutes), until therapeutic response is achieved. As soon as women were stabilized, labour was induced, accelerated or caesarean section done if obstetric indication demanded. In all patients with eclampsia maternal outcome was measured in terms of complications like pulmonary edema, hematological disorder, renal failure, abruption, cerebral hemorrhage and maternal death. Perinatal outcome was noted in terms of pre-term births, low birth weight, need of admission in nursery, IUGR, still births and neonatal deaths. All the data was tabulated in a pretested proforma and was analyzed using appropriate statistical methods.

\section{RESULTS}

Age and parity distribution (Table 1) of the total 50 cases, eclampsia was detected in pregnant women in younger age group viz., <25 years of age and is more common in primigravida when compared to multigravida. A decreasing trend was observed in incidence of eclampsia with the advancement of age.

Table 1: Age distribution and parity.

\begin{tabular}{|lll|}
\hline Age (years) & Primigravida (\%) & Multigravida (\%) \\
\hline $15-20$ & $14(28)$ & - \\
\hline $21-25$ & $20(40)$ & $06(12)$ \\
\hline $26-30$ & $04(08)$ & $04(08)$ \\
\hline $31-35$ & $01(02)$ & $01(02)$ \\
\hline$>35$ & - & - \\
\hline
\end{tabular}

\section{Eclampsia and maternal mortality}

As per mortality of cases is concerned. All the cases were effectively managed with appropriate intervention. Most of the patients developed eclampsia well before the onset of labour (Table 2).

Table 2: Eclampsia and maternal mortality.

\begin{tabular}{|llll|}
\hline Type & No of cases & Alive & Dead \\
\hline Antepartum & 36 & 36 & -- \\
\hline Intrapartum & 02 & 01 & -- \\
\hline Postpartum & 12 & 12 & -- \\
\hline
\end{tabular}

\section{Incidence of eclampsia in relation to antenatal care}

The incidence of eclampsia and its sequalae were found in pregnant women who didn't received antenatal care as seen in $90 \%$ of cases and only 5 cases amounting to $10 \%$ of cases who are booked cases went in to eclampsia (Table 3).

Table 3: Eclampsia and antenatal care.

\begin{tabular}{|lll|}
\hline Antenatal care & Number of patients & $\%$ \\
\hline Unbooked & 45 & 90 \\
\hline Booked & 05 & 10 \\
\hline
\end{tabular}

\section{Gestational age and onset of convulsions}

In the current study, convulsions are seen commonly after 37 weeks of gestation as evident in $52.6 \%$ of case and no convulsions history was present in pregnant women less than 25 weeks of gestation (Table 4). 
Table 4: Gestational age in weeks of patients at the onset of convulsions.

\begin{tabular}{|lll|}
\hline GA in weeks & Number of patients & $\%$ \\
\hline $20-25$ & - & - \\
\hline $26-31$ & 08 & 21.1 \\
\hline $32-37$ & 10 & 26.3 \\
\hline$>37$ & 20 & 52.6 \\
\hline
\end{tabular}

\section{Hypertension at presentation}

The blood pressure recording in most of the cases at presentation was less than or equal to $160 / 110 \mathrm{mmHg}$ as evident in $60 \%$ of cases but blood pressure was not normal in those cases. $15 \%$ of cases presented with severe hypertension of more than $160 \mathrm{mmHg}$ of systolic hypertension. However, $10 \%$ of subjects had normal blood pressures at presentation (Table 5).

Table 5: Blood pressure at presentation.

\begin{tabular}{|lll|}
\hline BP in mmHg & Number of cases & $\%$ \\
\hline Severe $\geq 160 / 110$ & 15 & 30 \\
\hline$\leq 160 / 110$ & 30 & 60 \\
\hline Normal & 05 & 10 \\
\hline
\end{tabular}

Fit to delivery interval and maternal outcome

Most $(60 \%)$ of the eclamptic patients delivered their babies in less than 12-24 hours after the onset of seizures (fit to delivery interval) (Table 6).

Table 6: Fit to delivery interval and maternal outcome.

\begin{tabular}{|llll|}
\hline In hours & Number of patients & Live & Dead \\
\hline$<6$ & - & - & - \\
\hline $6-12$ & 04 & 04 & - \\
\hline $12-24$ & 30 & 30 & - \\
\hline$>24$ & 04 & 04 & - \\
\hline
\end{tabular}

\section{Eclampsia and mode of delivery}

In the current study $52 \%$ of cases delivered through normal vaginal means, while $44 \%$ people underwent lower segment caesarean section and in two cases forceps delivery were conducted. (Table 7)

Table 7: Mode of delivery.

\begin{tabular}{|lll|}
\hline Mode of delivery & Number of patients & $\%$ \\
\hline Normal vaginal & 26 & 52 \\
\hline Caesarean & 22 & 44 \\
\hline Forceps/ventouse & 02 & 04 \\
\hline
\end{tabular}

History of seizure episodes before initiation of treatment

35 patients presented with history of less than two episodes of seizures before onset of treatment. Only one case presented with more than 5 episodes of convulsions (Table 8).

Table 8: History of convulsions before the start of treatment.

\begin{tabular}{|l|l|}
\hline No of convulsions & No. of cases \\
\hline $1-2$ & 35 \\
\hline $2-5$ & 14 \\
\hline$>5$ & 01 \\
\hline Coma & 00 \\
\hline
\end{tabular}

\section{Eclampsia and its complications}

A total of 13 cases amounting to $26 \%$ presented the established complications and were managed successfully. The commonest complication encountered was pulmonary edema, followed by HELLP syndrome, abruption and postpartum haemorrhage (Table 9).

Table 9: Maternal complications

\begin{tabular}{|ll|}
\hline Complications & Number of patients \\
\hline Abruption & 02 \\
\hline Cerebro vascular accident & 01 \\
\hline Pulmonary edema & 04 \\
\hline HELLP syndrome & 03 \\
\hline DIC & 01 \\
\hline PPH & 02 \\
\hline Total & 13 \\
\hline
\end{tabular}

\section{Eclampsia and perinatal outcome}

There were 14 perinatal deaths in eclampsia patients, giving a perinatal mortality rate of 280/1000. The perinatal outcome is depicted in the Table 10.

Table 10: Perinatal outcome.

\begin{tabular}{|c|c|}
\hline & No. of cases \\
\hline \multicolumn{2}{|l|}{ GA at delivery } \\
\hline$<37$ weeks & 30 \\
\hline$>37$ weeks & 20 \\
\hline \multicolumn{2}{|l|}{ APGAR score at $5 \mathrm{~min}$} \\
\hline$<6$ & 16 \\
\hline$\geq 6$ & 34 \\
\hline \multicolumn{2}{|l|}{ Out come } \\
\hline Stillbirth & 04 \\
\hline Early neonatal death & 10 \\
\hline Alive & 36 \\
\hline \multicolumn{2}{|c|}{ Cause of early neonatal death } \\
\hline Birth asphyxia & 04 \\
\hline Prematurity & 06 \\
\hline \multicolumn{2}{|l|}{ Birth weight } \\
\hline Low birth weight & 26 \\
\hline Normal birth weight & 24 \\
\hline
\end{tabular}




\section{DISCUSSION}

The incidence of eclampsia in the current study was $0.58 \%$, which is almost similar to a study conducted by Sunitha T.H et al $(0.7 \%)$ in a tertiary hospital in Karnataka state, India. ${ }^{10}$ However, it is observed that these figures are quite higher when compared to incidence in developed countries like the United Kingdom (UK), where eclampsia complicates only 0.05 $\%$ of total deliveries. ${ }^{11}$

One of the observations of the current study is that eclampsia was comparatively common in young pregnant women $(80 \%)$ and that too in primigravidas $(78 \%)$ tallies with the observations made a study done by Acharya $\mathrm{G}$ et al $(71.42 \%) .{ }^{12}$ The finding demands regular and compulsory screening of young pregnant ladies for preeclampsia/eclampsia.

It is a noteworthy finding that $90 \%$ of patients of eclampsia managed in our hospital were not registered with us for antenatal care. About $45 \%$ of patients did not receive any antenatal care at all and around $55 \%$ of the patients had some sort of antenatal care. Lack of antenatal care is a serious concern and appropriate steps are to be taken by the government to tackle with the menace of eclampsia. The same factor was recognized in a study conducted by Jain S et al, where in $93.99 \%$ of the study group didn't receive any sort of antenatal care. ${ }^{13}$ Only $10 \%$ of our booked cases had presented with eclampsia.

It can be stated based on the studies conducted in developed countries that incidence of eclampsia is quite unpredictable and ranges from $31 \%$ to $87 \%$ may be attributed to atypical presentation of eclampsia like abrupt onset, development of convulsions while receiving prophylactic Magnesium sulfate or onset of convulsions after 48 hours of delivery or in patients without hypertension or proteinuria. But in developing countries, the preventable causes of eclampsia contribute to most cases of eclampsia because of poor antenatal care services.

It is observed that $72 \%$ of eclampsia was antepartum, $4 \%$ were intrapartum and $24 \%$ were postpartum. As the high prevalence of antepartum eclampsia again reiterates the need for antenatal care significance.

The finding of this study that eclampsia was present in $52.6 \%$ of patients at term gestation is similar to a study done by Marinakhanum et al where the incidence was $53 \% .^{14}$

$30 \%$ of patients had severe hypertension at presentation, $10 \%$ had normal BP recording at presentation. A study conducted by Matter $\mathrm{F}$ et al quoted that $16 \%$ of the patients of their study had no hypertension, $20 \%-54 \%$ of them had severe hypertension and 30\%-60\% had mild hypertension. ${ }^{15}$ Hypertension is considered to be the hallmark for the diagnosis of eclampsia and hence all the pregnancy cases should be closely monitored for hypertension.

Cesarean section was one of the common modes of intervention in our series $(44 \%)$ which is similar to a study conducted by Sunitha TH et al. ${ }^{10}$ This study opine that eclampsia per se is not an indication for cesarean section and mode of delivery had no significant effect on the outcome of the eclamptic as cited by Ibrahim A et al. $^{16}$

The decision to perform cesarean section should be based on fetal gestational age, fetal condition and presence of associated obstetric indications (mal presentations or the other high risk factors), cervical bishop score and maternal condition but not merely by the presence of eclampsia.

In this study on eclampsia, labour is induced with one of the methods such as usage of prostaglandins, early rupture of membranes wherein the obstetrician can monitor and await vaginal delivery once the patient is stable and convulsions are under control. Judicious and timely selection of cases for either vaginal delivery or for cesarean section is the key to improve the maternal and perinatal outcome.

There are increased rates of maternal morbidities due to eclampsia as depicted in Table 9. There were 14 perinatal deaths resulting in pregnancies associated eclampsia. The most common causes of perinatal death are prematurity, fetal growth restriction, fetal asphyxia and acidosis.

According to the Royal college of obstetricians and gynecologists (RCOG) good antenatal services will detect and treat preeclampsia and thus reduce the incidence of eclampsia. Prompt and timely treatment of eclampsia will reduce the maternal and perinatal morbidity and mortality. $^{17}$

\section{CONCLUSION}

The study concluded that eclampsia continues to be one of the prime etiological factors for maternal/perinatal morbidity and mortality. The commonest contributory factors for this are lack of proper antenatal care, low socio economic status and lack of education. Most of these factors can be easily controlled and there is an urgent need for proper antenatal care, proper medication (magnesium sulfate), intensive monitoring of women with eclampsia and timely hospitalization to improve both the maternal and perinatal outcome. The same fact is established in the current study and also in other studies conducted in the country as well as other countries. In complicated cases early presentation to the hospital and timely decision of management as to early termination of pregnancy will certainly improve the maternal and perinatal outcome. 


\section{ACKNOWLEDGEMENTS}

The authors extend their sincere thanks to all the authors whose references/articles are cited/used in this article. Any constructive criticisms/suggestions are humbly welcomed.

Funding: No funding sources Conflict of interest: None declared

Ethical approval: The study was approved by the Institutional Ethics Committee

\section{REFERENCES}

1. Andersgaard AB, Herbst A, Johansen M. Eclampsia in scandinavia: incidence, substandard care, and potentially preventable cases. Acta Obstet Gynecol Scand. 2006;85(8):929-36.

2. Swain S, Ohha KN, Prakash A. Maternal and perinatal mortality due to eclampsia. Indian Pediatr. 1993;30(6):771-3.

3. Urassa DP, Carlstedt A, Nystrom L, Massawe SN, Lindmark G. Eclampsia in dar es salaam, Tanzania incidence, outcome, and the role of antenatal care. Acta Obstet Gynecol Scand. 2006;85(5):571-8.

4. Obed S, Aniteye P. Pregnancy following eclampsia: a longitudinal study at Korle-BU teaching hospital. Ghana Med J. 2007;20:139-43.

5. Sibai BM. Eclampsia. Maternal-perinatal outcome in 254 consecutive cases. Am J Obstet Gynecol. 1990;163(3):1049-54.

6. Saha S, Saha A. Clinical audit of perinatal mortality a reappraisal of major determinants and its prevention. J Obstet Gynecol Ind. 2002;52:83-6.

7. Urassa D, Carlstedt A, Nystrom L, Msamanga G. Management of hypertension in pregnancy as a quality indicator of antenatal care in rural Tanzania. Afr J Reproductive Health. 2003;7:69-76.

8. Alan H, Nathan L, Murphy $\mathrm{T}$, Laufer $\mathrm{N}$. Hypertension in pregnancy. Current diagnosis and treatment in Obstetric and Gynaecology. $10^{\text {th }}$ edition. New York, NY:McGraw-Hill;2007:318-328.

9. Cunningham F, Kenneth J, Bloom S, Hauth J, Larry C, Wenstrom K. Hypertensive disorders in pregnancy. Williams Obstetrics. 22 $2^{\text {th }}$ edition. New York, NY:McGraw-Hill;2007:761-809.

10. Sunita TH, Desai RM. Eclampsia in a teaching hospital: incidence, clinical profile and response to magnesium sulphate by zuspan's regimen. J Dental Med Sci. 2013;4(2):1-5.

11. Douglas KA, Redman CW. Eclampsia in the United Kingdom. British Med J. 1994;309(6966):1395-400.

12. Acharya G, Schultz S. Eclampsia in Patan hospital: a two year retrospective study. J Nepal Med Asso. 1991;29:254-8.

13. Jain S, Nager S, Monga D. Maternal mortality following eclampsia; a critical analysis of 693 cases in two teaching hospitals in Northern India. 1998;38:256-60.

14. Khanum M, Ashraf F, Sahrin H. A clinical study of 100 cases of eclampsia in Rajshahi medical college hospital. Transactional Analysis J. 2004;17(2):80-3.

15. Mattar, F, Sibai BM. Eclampsia risk factors for maternal morbidity. Am J Obstet Gynecol. 1990;163:1049-55.

16. Ibrahim A, Yakasai, Sule A, Gaya. Maternal and fetal outcome in patients with eclampsia at murtala muhammad specialist hospita Kano, Nigeria. Annals African Medicine. 2011;10(4):305-9.

17. Onwuhafua PI, Onwuhafua A, Adze J, Mairami Z. Eclampsia in Kaduna state of Nigeria. a proposal for a better outcome. Niger J Med. 2001;10:81-4.

Cite this article as: Shaikh SB, Jampala S, Devi SS, Mallika. A study on maternal and perinatal out comes in cases of eclampsia admitting to government medical college and general hospital, Anantapuramu, Andhra Pradesh, India. Int J Reprod Contracept Obstet Gynecol 2016;5:2146-50. 